\title{
XL. Minimum Spark Potentials
}

\section{John E. Almy Ph.D.}

To cite this article: John E. Almy Ph.D. (1908) XL. Minimum Spark Potentials, Philosophical Magazine Series 6, 16:93, 456-462, DOI: 10.1080/14786440908636528

To link to this article: http://dx.doi.org/10.1080/14786440908636528

$$
\text { 册 Published online: } 21 \text { Apr } 2009 .
$$

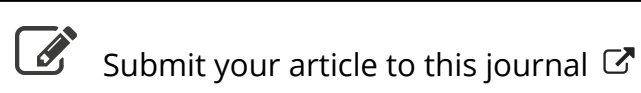

\footnotetext{
Џll Article views: 2
}

Q View related articles ¿

Citing articles: 8 View citing articles $\square$ 
quite masked over any effect due to elongation of the wire by expansion of the shellac.

It will be seen that our observations do on the whole support the conclusions arrived at by Drs. Rosa and Babcock, and that coils hermetically sealed, or coated with a varnish which does not absorb moisture, must have an advantage over manganin coils coated with shellac. The fact that some high-resistance coils exhibit the "humidity effect" to a negligible extent only, points to the possibility that a shellac varnish may be prepared, which, after baking, is notappreciably hygroscopic.

\section{Minimum Spark Potentials. \\ By John E. Almy, Pl.D.**}

RECENT work of Earhart†, Shaw + , Hobbs §, and 12 Kinsley \| dealing with spark potentials for very short spark-gaps seem to show that the spark-discharge may take place at poientials far below the so-called "minimum sparkpotential." These results, so signally at variance with the results of Carr T and others, who have found every evidence of a minimum value of potential, below which it was impossible to obtain a discharge with any spark-gap or any gas pressure whatever, seem to require further careful investigation.

At first, two spark electrodes were mounted upon an interferometer of the Fabry-Perot type, one electrode being carried upon the table that carries the movable plate of the interferometer, the other being fixed adjacent to the second plate of the interferometer. The supports were fairly rigid, being of massive brass plates, reinforced. In attempting to use electrodes which were segments of a sphere of $5 \mathrm{~cm}$. radius, and later, using spheres of $1 \mathrm{~cm}$. radius, it was noted that a discharge, or at any rate a short-circuit of the discharge circuit, was obtained with potentials considerably below the "minimum potential" (about 350 volts in air at atmospheric pressure), but that when this occurred the electrodes were invariably drawn together and remained fused together ; while in case the potential was raised above the minimum potential this fusing together of the electrodes rarely if ever results. It sometimes happened that with

* Communicated by the Author.

+ Earhart, Phil. Mag. [6] i. p. 147 (1901).

I Shaw, Proc. Roy. Soc. Ixxii. p. 337 (1903).

\$ Hobbs, Phil. Mag. [6] x. p. 617 (1905).

II Kinsley, Phil. Mag. [G] ix. p. 692 (1905).

7 Carr, Yroc. Roy. Soc. Ixxi. p. 374 (1903). 
potentials near 350 volts a rapid series of discharges or short-circuits would occur, accompanied by a humming note very like that of the Trevelyan rocker; evidently the electrodes were set in rapid vibration by the electrostatic force between the charged electrodes. Clearly the supports were not sufficiently rigid.

This phenomenon suggests the possibility that what have been considered spark-potentials for very short sparks may not have been at all the potentials required to give a disruptive discharge through the gas between the electrodes, but were rather the potentials necessary to give sufficient electrostatic attraction between the electrodes to cause a displacement equal to the spark-gap, thus bringing the electrodes in contact. If this be true, the potential required to effect a discharge, with these short distances, would be a function of the size of the electrode, especially if that size were comparable in magnitude to the spark-gap.

In order to investigate this question the following apparatus was devised: Spherical electrodes of minute dimension were obtained by fusing in the oxy-hydrogen flame the end of fine platinum wire, $.0057 \mathrm{~cm}$. in diameter; the smallest spheres thus formed had a radius very approximately $\cdot 0035 \mathrm{~cm}$. and were essentially true spheres. Two such electrodes were mounted on the interferometer, as shown in fig. 1 (horizontal

Fig. 1.

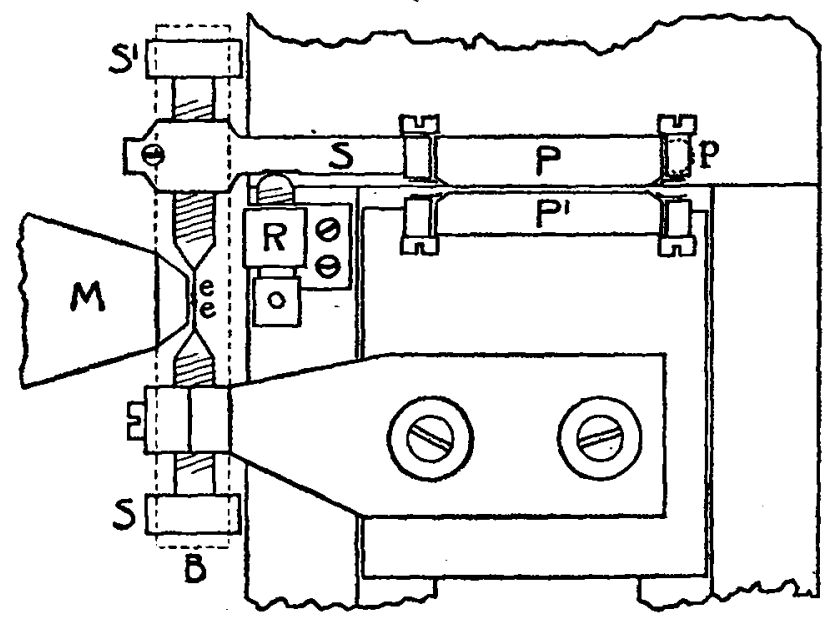

section). The electrodes $e e$ are carried on screws that thread very tightly tbrough the steel supports; one support is rigidly clamped to the moving carriage of the interferometer, 
being insulated by ebonite ; the second, $\mathrm{S}$, is carried on the frame which carries one plate of the interferometer, this plate, $\mathrm{P}$, being supported on a post, $p$, about which, as a vertical axis, it is free to rotate but for the stop $R$, which was made as rigid as the other parts of the apparatus. To take up "back lash" and any looseness in the adjustment of parts, a number of strong indiarubber bands, B B, were stretched around the electrodes pressing upon the screw heads, $s s$; a high-power microscope M, placed horizontally, made possible the careful alignment of the minute electrodes, and enabled one to follow visually the course of effects. Without the rubber bands it was impossible to get the system sufficiently rigid so that the electrodes were not visibly moved when potentials near 300 volts were applied to sparkgaps of a few wave-lengths of sodium light; with the bands in place the separation of the electrodes follows promptly the displacements of the bands of the interferometer, and that the rubber bands did not affect the accuracy of the interferometer in the measurement of the spark-gap, at least so far as the motion of the interferometer plates is concerned, was shown by determinations of the wave-length of sodium light, in which the same values were obtained with and without the rubber bands in place.

The electrical system used was the usual one; a battery of storage-cells gave 1200 volts potential, this was connected through a cadmium-iodide-amyl-alcohol resistance to earth ; the spark-gap and a Weston voltmeter, in parallel, were shunted on this resistance with movable electrode in the iodide solution, so the potential applied to the spark-gap could be varied at will and read off directly. For a time, an auxiliary circuit with $2 \cdot 2$ volts and a galvanometer were used to detect short circuit of the spark-gap, but the settings made in this way proved less definite and capable of repetition than those made with from 10 to 20 volts on the regular spark circuit. The method of procedure was usually this : With the electrodes clearly in contact at the start, they were moved apart by steps of 11 wave-length $(\mathrm{Na})$, testing with the 10 volts for a short circuit after each step; as soon as open circuit was obtained the electrodes were then separated by a certain number of wave-lengths and the potential gradually raised to a value somewhat less than the "minimum potential"; if, after waiting a sufficient interval, this potential failed to give a discharge, the spark-gap was decreased by a wavelength and again tested; when this process had been repeated until the spark-gap was unquestionably extremely small and had been subjected to the high potential several minutes 
with no evidence of discharge, the potential was reduced to 10 volts and the distance measured through which the electrodes needed to move to give short circuit. For example, using two platinum spheres each approximately $007 \mathrm{~cm}$. in diameter the following observations are noted:

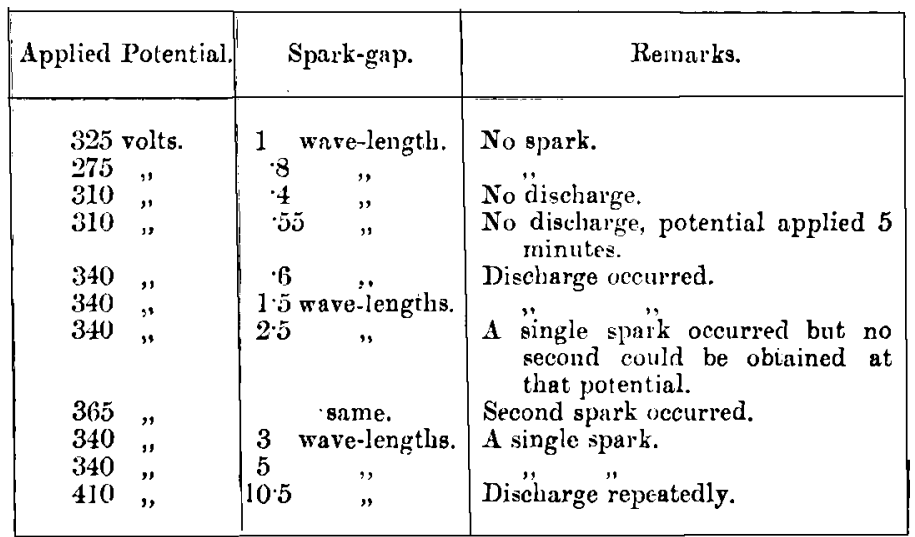

Using spheres of unequal size, with diameters $008 \mathrm{~cm}$. and $\cdot 0057 \mathrm{~cm}$. the following results were obtained :

280 volts; no discharge; gap measured 8 ware-length.

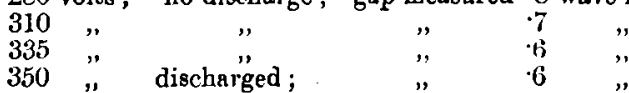

Next a pair of steel needles were substituted for the minute spheres. Needle-points are by no means geometrically pointed, but are usually more approximately parabolic, in the axial section. The appearance of the needles used, as seen in the microscope, is shown in fig. 2; the diameter at a

Fig. 2.

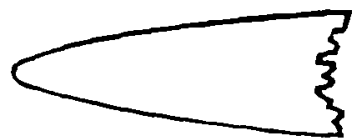

distance from the tip equal to the radius of curvature at the tip was approximately $\cdot 0007 \mathrm{~cm}$. With two such electrodes the following observations dealing with spark-gaps of less than a wave-length of sodium light were made :

320 volte applied; no discharge; gap measured 9 wave-length.
330
330
" on" 5 minutes, no
"
$7 \quad$ "
330
", applied; no discharge ; gap measured 25 
By taking a definite spark-gap and gradually increasing the applied potential until a discharge, or short-circuit, resulted, the following observations were made:

Spark-gap, 15 wave-length; at 270 volts c1rcuit closed, no discharge was observable in the microscope.

Spark-gap, $\cdot 2$ wave-length; at 345 rolts circuit closed, electrodes were found to be fused together.

Spark-gap -35 wave-length; at 360 volts a spark passed, clearly visible, circuit remained opened for lower potentials.

The evidence seems conclusive that with spark-gaps down to at least $\cdot 3$ wave-length of $\mathrm{Na}$ light, that is, $\cdot 0000177 \mathrm{~cm}$. a potential of 330 volts is not sufficient to produce discharge through air at atmospheric pressure, while 360 volts is sufficient to do so.

It is of interest to notice the nature of the discharge with these minute spark-gaps. Through the microscope (magnifying about 500 times), the discharge that occurs with potentials near the "minimum potential" is seen to be a quiet luminous glow discharge, the luminescence beginning at a point somewhat back from the needle tip, completely surrounding the needle and extending back along the needle (one electrode only), exactly similar to the negative glow around a cathode in gas at low pressure. But at the tip of the needle no luminosity was evident. While with higher potentials a brilliant, concentrated, discharge passed in a more limited path, appearing in the microscope much like a long arcdischarge results. With a gap of several wave-lengths on a few occasions the passing of scintillating particles (dust or metallic?) from one electrode to the other was noticed ; once or twice this occurred with potentials below the "minimum," but could not be repeated. The following observations made with steel needles as electrodes are illustrative (p. 461).

It seems conclusive from the observations given that, at any rate when minute electrodes, comparable in size to the size of the spark-gap, are used, there is a "minimum potential" below which, no matter what the spark-gap, a true spark-discharge does not take place. And there seems large probability that Paschen's law of inverse proportionality of spark-length to gas pressure is equally applicable to spark-gaps shorter than that corresponding to the "minimum potential." Some work has been done to verify this, with fair success at pressures below atmospheric; at atmospheric pressures the distances concerned are so extremely small that the problem of determining the sparking potential, when the discharge is compelled to pass through the short path, is one of great difficulty. The results obtained will be given in a later paper. 
Minimum Spark Potentials.

\begin{tabular}{|c|c|c|c|}
\hline $\begin{array}{c}\text { Spark-Gap } \\
\text { (wave-lengths). }\end{array}$ & $\begin{array}{l}\text { Potential } \\
\text { (volts). }\end{array}$ & \multicolumn{2}{|c|}{ Remarks. } \\
\hline $\begin{array}{l}+t \\
-3\end{array}$ & $\begin{array}{l}345 \\
345 \\
350\end{array}$ & \multicolumn{2}{|l|}{$\begin{array}{l}\text { No discharge. } \\
\text { Glow discharge. }\end{array}$} \\
\hline $1 \cdot 0$ & $\begin{array}{l}345 \\
350\end{array}$ & \multicolumn{2}{|l|}{$\begin{array}{l}\text { No discharge. } \\
\text { Glow discharge. }\end{array}$} \\
\hline $\begin{array}{l}1.5 \\
2 \cdot \overline{5}\end{array}$ & $\begin{array}{l}345 \\
350 \\
345 \\
350\end{array}$ & \multicolumn{2}{|l|}{$\begin{array}{l}\text { No discharge. } \\
\text { Glow diseharge. } \\
\text { No discharge. } \\
\text { Glow discharge. }\end{array}$} \\
\hline $4 \cdot 0$ & $\begin{array}{l}345 \\
350\end{array}$ & \multicolumn{2}{|l|}{$\begin{array}{l}\text { No discharge, } \\
\text { Glow discharge. }\end{array}$} \\
\hline $7 \cdot 5$ & $\begin{array}{l}320 \\
350 \\
440\end{array}$ & \multicolumn{2}{|c|}{$\begin{array}{l}\text { Scintillation : ceased immeúiateiy. } \\
\text { Glow discharge; continuous. } \\
\text { Arc discharge produced. }\end{array}$} \\
\hline $9 \cdot 0$ & 490 & \multicolumn{2}{|c|}{ Are discharge; no glow obtained. } \\
\hline 10.0 & 505 & ", $\quad$ " & $"$ \\
\hline 12.5 & 530 & $"$ & $"$ \\
\hline 150 & 600 & $"$ & $"$ \\
\hline
\end{tabular}

Considering the electrostatic force which exists between two large electrodes bronght within such minute distances as were used by Earhart, Shaw, and Hobbs, it seems not wholly improbable that the strains sufficient to bring their electrodes into contact may have occurred with potentials less than the "minimum." So that the potentials that produce a short circuit in the spark-gap were simply those required to give the requisite displacement of the electrodes.

In connexion with this question of short sparks, attention may be called to the fact that Earhart*, and Shaw $t$, in recent work upon spark potentials in liquid dielectries have apparently made no attempt to ensure absence of dust or other foreign particles from the liquids tested. True, Earhart gives as argument for this disregard the fact that the sparkpotential for the second and succeeding sparks was the same as the first, but that is, in truth, evidence showing that the dust already present does affect the discharge potentials. It is well known that the passage of a spark in any insulating oil invariably results in the formation of carbon particles, and these particles collect between the electrodes, and it hardly seems probable that the presence of particles of so

* Earhart, Phys. Rev. xxiii. p. 358 (1906).

† Shaw, Phil. Mrg. [6] p. 317 (1906). 
good a conducting material as carbon in the spark-gap could be entirely without effect upon the discharge. Rather, it seems likely that the particles present before the first spark were as effective as carbon particles. The writer* has shown clearly that the passage of a spark through an oil does very materially affect the potential required to produce the discharge. So that, valuable as the results of Earhart and Shaw are as representing the actual working conditions which usually obtain, they may not be taken to represent the potentials necessary to produce spark discharges through the distances given, in the pure liquid.

The Brace Laboratory, Lincoln, Nebr., U.S.A.

XLI. The Greenhouse Theory and Planetary Temperatures. By Frank W. Very†.

W HEN Tyndall, as the result of his measures of the absorption of terrestrial radiation by water-vapour, assured us that the removal of moisture from its atmospheric covering would plunge the British Isles into a more than Arctic winter, he directed attention to that which, next to the solar radiation itself, is the most potent factor in terrestrial climate. In a general way this is now universally recognized; but we have not yet arrived at unanimity as to the details of the process by which this protective agency works, or of their applicability to other worlds than ours.

Never having had any experience with gases devoid of convection, nor with solids lacking thermal conductivity, it is perhaps hardly safe to speculate as to bow such substances would or would not behave; but if a guess may be hazarded on the subject of Professor Poynting's ideal greenhouse $\neq$, one would suppose that if the background were absolutely nonconducting, unless it were a perfect reflector, in which case it would not be heated at all, the heating effect of solar rays would be increased in something like the proportion of six to one even without any glass. For if we suppose cubical particles, each containing a cubic centimetre of perfectly absorbing and conducting substance, to be maintained in the sun's rays at an excess of $10^{\circ}$ above an initial temperature of $300^{\circ} \mathrm{A}$., and then reduce the thickness of the normal absorbing

* Almy, Ann. der Phys. [4] i. p. 508 (1900).

+ Communicated by the Author.

$\mp$ J. H. Poynting, "On Prof. Lowell's Method for Evaluating the Surface Temperatures of the Planets," Phil. Mag. [6] vol. xiv. p. 749, December 1907. 